\title{
Evaluation of the Influence of Grain Structure on the Fatigue Variability of Waspaloy
}

\author{
Mandy L. Brogdon ${ }^{2}$ and Andrew H. Rosenberger ${ }^{1}$ \\ ${ }^{1}$ Air Force Research Laboratory, Material \& Manufacturing Directorate, AFRL/RXLMN, Wright-Patterson AFB, OH 45433-7817, USA \\ ${ }^{2}$ University of Dayton Research Institute, Dayton, OH 45469-0128, USA, currently at University of Pittsburgh, Pittsburgh, PA, USA
}

Keywords: Fatigue variability, life modeling, elevated temperature

\begin{abstract}
Considerable effort is spent controlling the microstructure of superalloys that are used in fracture critical rotating structures for gas turbine engines. It is generally understood that a controlled, uniform microstructure is necessary for the best, most uniform mechanical properties. The aim of this effort was to evaluate this assumption in Waslapoy using a new approach to assess a material's fatigue performance. Repeat fatigue tests were conducted at $538^{\circ} \mathrm{C}$ on two microstructural variants of this material to assess both the worst case fatigue and average fatigue properties, knowing that the lower limit fatigue life is the most important yet most materials and processes are developed on the basis of average properties. The lower limit of fatigue capability was found to be controlled by the largest grain size in the microstructure - not on the overall variation in grain size. This lower limit was also rationalized using a fracture mechanics approach wherein the shortest fatigue life was found to match the integration of the crack growth curve starting at the maximum observed grain size.
\end{abstract}

\section{Introduction}

Waspaloy is one of the most widely used materials in the gas turbine engine industry that is produced using conventional ingot metallurgy. Care is taken in its processing [1] to ensure microstructural homogeneity to result in consistent mechanical properties for critical rotating structures. All fracture critical aeroengine structures are designed using a safe fatigue life methodology that is based on the minimum fatigue capability (though the USAF also adds a damage tolerant criterion [2]). The thought is that strict microstructural control will lead to reduced fatigue scatter and, therefore, a higher usable stress for a similar risk of failure. However, a systematic study of the relation between the microstructure (and its variability) on the fatigue variability has not been conducted for Wasplaoy.

The approach developed by Jha and Ravi Chandran [3] points out the limitations of the traditional stress-life characterization of a material. Specifically, there are not enough data to fully characterize the left tail of the fatigue distribution in the conventional approach and conservative (or anticonservative) estimates of the $-3 \sigma$ fatigue limits can result. This new approach uses a number of repeat specimens at fewer stress levels to assess the scatter in fatigue for a material. Typically each stress level has 10 to 30 replicate tests to more accurately determine the tails of the fatigue distribution. Though this is costly, it is provides a better understanding of the mechanisms of fatigue crack initiation which is critical for developing a robust understanding of a material or process. For example, this approach has been utilized to assess the improved fatigue properties in a Ti-6al-4V alloy that is reinforced with $\mathrm{TiB}_{2}$ particulates [4]. This method was chosen to assess the influence of boron level and the uniformity of the boride distribution. Rather than develop an alloy on average properties, this method pointed out the strengths and weakness of the current alloy and guided technologies to improve the material. The approach has also been applied to other superalloys, [5] and titanium alloys $[5,6]$ where it has the ability to separate the different mechanisms of failure for the material under interrogation and better assess the fatigue minimums.

To carefully assess the role of microstructural variability in Waspaloy, replicate fatigue tests were conducted on specially processed material to assess the fatigue variability. The number of repeats was high to understand a subtle difference in microstructure.

\section{Material and Experimental Details}

The Waspaloy specimen blanks were extracted from a specially produced extrusion for the specific purpose to produce a variation in the microstructure from the center of the billet to the outer diameter. This product was known to not conform to the high commercial material standards [1] and was known to contain stray, large grains, termed as-large-as or ALA grains, near the outer diameter. The regions of ALA grains were determined to be within $12 \mathrm{~mm}$ of the outer diameter. Cylindrical fatigue blanks were extracted (by EDM) from the locations in billet containing the desired microstructure for this study. The fatigue samples were a buttonhead, cylindrical dogbone geometry. The nominal length of the samples was $145 \mathrm{~mm}$, with a reduced gage section of $5.1 \mathrm{~mm}$ in diameter and $15.2 \mathrm{~mm}$ in length. Only the central $\sim 45$ $\mathrm{mm}$ of the sample is Waspaloy and the ends are inertial welded IN 718 to conserve the test material and more accurately locate the gage length of the sample in the billet for better microstructural selection. The buttonhead geometry allows for simple and speedy test setup and minimizes any experimental variability due to alignment errors. The specimens were also electropolished to eliminate any influence of machining residual stress that could affect the fatigue results. Compact tension, $\mathrm{C}(\mathrm{T})$, specimens were also extracted from the billet. These specimens had a width equal to $20 \mathrm{~mm}$ and a thickness of $5 \mathrm{~mm}$ and were oriented so the crack planes in the $\mathrm{C}(\mathrm{T})$ specimens matched that of the fatigue bars.

The specimen blanks were given a standard heat treatment for Waspaloy:

$-1850^{\circ} \mathrm{F}$ for one hour, then oil quenched

$-1550^{\circ} \mathrm{F}$ for four hours, then air cooled

$-1400^{\circ} \mathrm{F}$ for four hours then air cooled.

The two microstructural variants of the alloy are shown in Figure 1. Figure 1(A) shows the conventional microstructure for Waspaloy having an average ASTM grain size of 7 . The alternate, atypical material shown in Figure 1(B) shows a finer microstructure, having an average ASTM grain size of 8.5 with grains occasionally as large as ASTM 2 (ALA ASTM2). These 
materials will be called the "conventional" and "fine+ALA" materials, respectively.
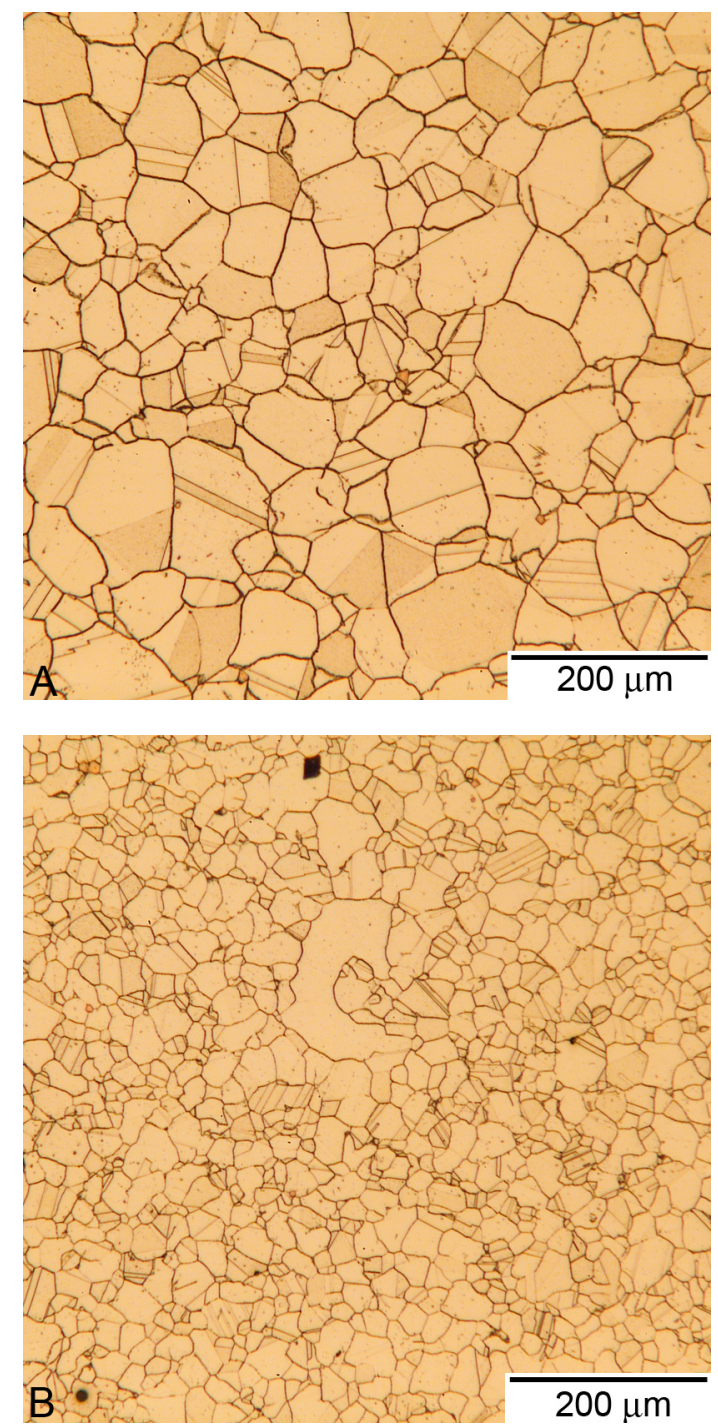

Figure 1, The two microstructural variants of Waspaloy used in the study; A) Conventional, and B) Fine + ALA.

The fine + ALA material is typically not desirable in fracture critical components as it is generally assumed that the large grains will be sites of stress localization and cause premature failure. Hence, effort is made to produce a uniform microstructure. Details of the grain size distributions are shown in figure 2. The grain size cumulative distribution functions were obtained by carefully tracing the grains on several optical micrographs to obtain the planar area distributions that were then converted into the ASTM grain sizes shown using ASTM Standard, E112-96.

The CDF of grain size shown in figure 2 illustrates the problem with utilizing average grain size descriptors for a material. The conventional material has a larger average grain size than the fine + ALA material but has nearly the same largest grain size. The difference in largest grain size is less than 1 ASTM grain size between the two variants. The solid and dashed lines in the figure highlight the change in slope at larger grain size indicating a change in the distributions. The lines indicate the contribution of the ALA grains (solid) to the total distribution and what is believed to be the fine grain material without ALA grains (dashed). This shows that one would expect a grain size difference on the order of ASTM 3 without the ALA grains.

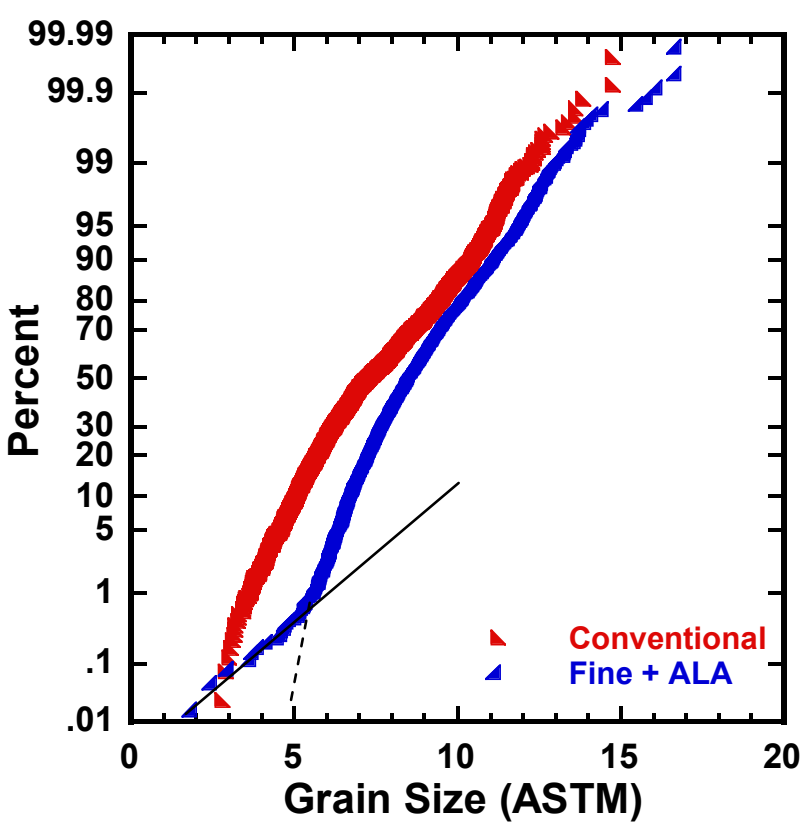

Figure 2, Grain size distributions for the two variants of Wasplaoy interrogated in this study.

All fatigue tests were conducted at $538^{\circ} \mathrm{C}$ in load control with a loading frequency of $1 \mathrm{~Hz}$ with a stress ratio, $\mathrm{R}$, equal to 0.05 . These test conditions were chosen such that the environment would slightly affect the crack growth behavior of the material so that cracks could be monitored on the surface to the specimen. Additional details of the material and experimental procedures can be found in the reference by Brogdon [7].

The crack growth tests were conducted first in a K-decreasing mode in general accordance with the ASTM E647-05 standard. The force was shed with a normalized K-gradient, $\mathrm{C}=1 / \mathrm{K} * \mathrm{dK} / \mathrm{da}$ $=-0.08 \mathrm{~mm}^{-1}$. Due to the small size of the specimen, the load was increased to the middle of the Paris region after reaching threshold and the test was completed using constant load amplitude. Repeat tests were conducted to assess any crack growth variability.

Fracture surfaces of all specimens were examined using scanning electron microscopy to assess the location of crack initiation and the fatigue initiation mechanism(s).

\section{Results and Discussion}

\section{$\underline{\text { Tensile Results }}$}

The tensile response of the two microstructures was first characterized to assess whether any substantial difference in fatigue response would be expected for the two materials. Tests were conducted (using the same geometry as the fatigue bars) at 
$538^{\circ} \mathrm{C}$ in displacement control with a strain rate of approximately $0.008 \mathrm{~s}^{-1}$. Average results and standard deviation for these tests are shown in Table 1.

Table 1, Tensile properties for the two variants of Wasplaoy, $538^{\circ} \mathrm{C}, 0.008 \mathrm{~s}^{-1}$.

\begin{tabular}{|c|c|c|c|c|}
\hline \multirow{2}{*}{ Material } & & YS $_{\mathbf{0 . 2}}$ & UTS & Modulus \\
\cline { 3 - 5 } & & $(\mathrm{MPa})$ & $(\mathrm{MPa})$ & $(\mathrm{GPa})$ \\
\hline \multirow{2}{*}{ Conventional } & Average & 807.79 & 1217.59 & 179.40 \\
\cline { 2 - 5 } & Std dev & 11.6 & 20.8 & 2.57 \\
\hline \multirow{2}{*}{ Fine +ALA } & Average & 731.60 & 1181.96 & 171.68 \\
\cline { 2 - 5 } & Std dev & 20.1 & 9.65 & 5.44 \\
\hline
\end{tabular}

It can be seen that the conventional material has a higher yield and slightly higher ultimate tensile strength than the fine + ALA material. It is interesting that the fine + ALA samples had more scatter in the yield strength and less in the UTS than the samples having the conventional microstructure. All samples exhibited tensile elongation to failure greater than $20 \%$. Initially it was thought that the conventional material might have better fatigue properties due to its higher strength but initial fatigue tests tended to indicate that tests conducted at a maximum stress of $955 \mathrm{MPa}$ would result in fatigue lives centered around $10^{5}$ cycles for both microstructural variants.

\section{$\underline{\text { Fatigue Results }}$}

More than 40 fatigue bars were produced from the two different microstructures of Waspaloy. Replicate fatigue tests were conducted at $538^{\circ} \mathrm{C}$ at $1 \mathrm{~Hz}$ with a stress ratio, $\mathrm{R}=0.05$. All the tests reported were conducted at a maximum stress of $955 \mathrm{MPa}$. Results for the tests are shown in Figure 3 in terms of a cumulative distribution function for cycles to failure. It can be seen that the bimodal material has considerably greater scatter than the conventional material yet both materials exhibit the same minimum fatigue life, on the order of 30,000 cycles. The average fatigue lives for the two microstructures (the 50th percentile) are nearly identical though the conventional has a slightly longer life than the fine + ALA microstructure. These were unexpected results. However, Figure 2 indicated that the grain size distribution in the conventional material has a relatively wide variation and does include grain sizes up to ASTM 3. This is not substantially smaller than the ALA grain size. Also the average grain size is not that different for the two microstructures nor is the slope of the grain size distribution in figure 2. So the average test bar, in both cases, likely contains some grains that are large enough to cause similar behavior. These fatigue results indicate the necessity in carefully quantifying the grain size distribution of a material rather than comparing a material on average grain size alone. The five specimens of the fine + ALA material that exhibited a substantially longer life appear to offer a third category of material behavior for this material. Some of these specimens exhibited internal failure which would explain the longer life, due to the fact that those cracks are growing in a vacuum, but some of the specimens failed from the surface. It is likely that these specimens did not contain the ALA grains in the gage length or failed to have such grains that were favorably oriented for crack initiation. So it is possible that the slightly finer microstructure may have a substantially better mean fatigue life and should bring in the left tail as well - if the material does not contain the distribution of large grains.

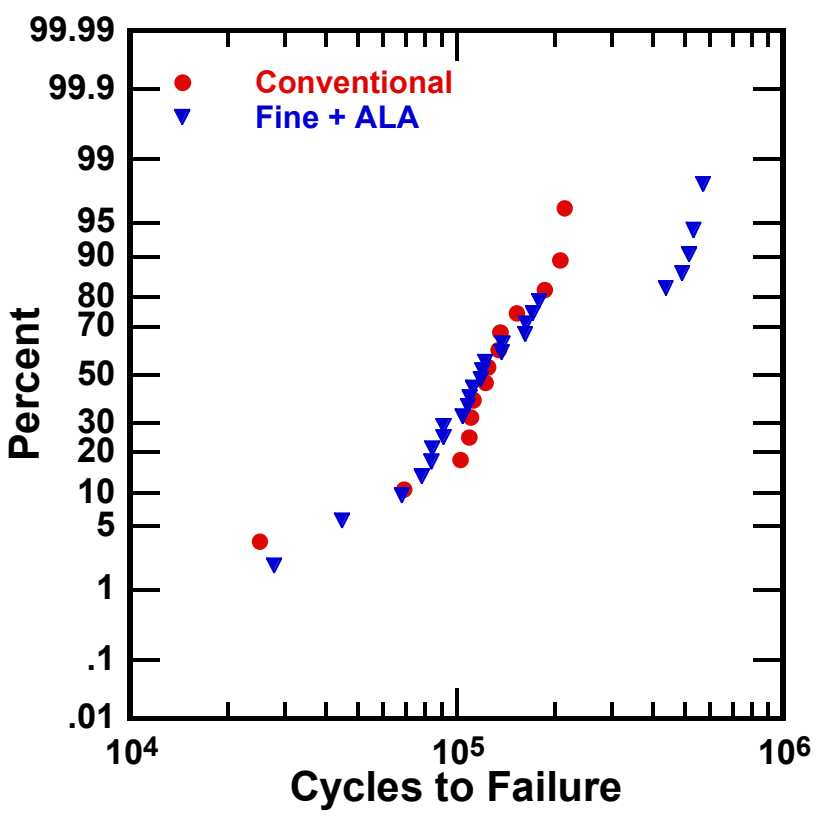

Figure 3, Fatigue life distribution for the two variants of Waslapoy, $538^{\circ} \mathrm{C}, \mathrm{R}=0.05, \sigma_{\max }=955 \mathrm{MPa}, 1 \mathrm{~Hz}$.

Crack Initiation Assessment A number of the fatigue tests were evaluated with acetate replicates to pinpoint the crack initiation event and to assess the fatigue mechanisms since most of the specimens initiated cracks on or near the surface. Results of this study are shown in Table 2.

Table 2, Surface crack length, initiation location, and cycles to failure from replication of select specimens.

\begin{tabular}{|c|c|c|c|c|}
\hline $\begin{array}{c}\text { Specimen } \\
\text { ID }\end{array}$ & $\begin{array}{c}2^{\text {nd }} \text { to Last } \\
\text { Replica }\end{array}$ & $\begin{array}{c}\text { Last } \\
\text { Replica }\end{array}$ & $\begin{array}{c}\text { Initiation } \\
\text { Depth }\end{array}$ & $\begin{array}{c}\text { Cycles to } \\
\text { Failure }\end{array}$ \\
\hline \multicolumn{5}{|c|}{ Conventional } \\
\hline \multirow{2}{*}{ 06-011 } & 110,000 & 120,000 & \multirow{2}{*}{$\begin{array}{l}\text { Just } \\
\text { subsurface }\end{array}$} & \multirow{2}{*}{122,719} \\
\hline & no crack & $849 \mu m$ & & \\
\hline \multirow{2}{*}{ 06-014 } & 100,000 & 110,000 & \multirow{2}{*}{$100 \mu \mathrm{m}$} & \multirow{2}{*}{110,006} \\
\hline & $192 \mu m$ & $2,063 \mu \mathrm{m}$ & & \\
\hline \multirow{2}{*}{ 06-024 } & 140,000 & 150,000 & \multirow{2}{*}{ unknown } & \multirow{2}{*}{152,658} \\
\hline & no crack & no crack & & \\
\hline \multirow{2}{*}{$06-026$} & 190,000 & 200,000 & \multirow{2}{*}{$100 \mu \mathrm{m}$} & \multirow{2}{*}{207,859} \\
\hline & no crack & no crack & & \\
\hline \multicolumn{5}{|c|}{ Fine + ALA } \\
\hline \multirow{2}{*}{$06-121$} & 120,000 & 130,000 & \multirow{2}{*}{$110 \mu \mathrm{m}$} & \multirow{2}{*}{137,819} \\
\hline & no crack & $151 \mu m$ & & \\
\hline \multirow{2}{*}{$06-131$} & 150,000 & 175,000 & \multirow{2}{*}{$50 \mu \mathrm{m}$} & \multirow{2}{*}{179,404} \\
\hline & $78 \mu m$ & $706 \mu m$ & & \\
\hline \multirow{2}{*}{$06-139$} & 120,000 & 130,000 & \multirow{2}{*}{$\begin{array}{l}\text { Just } \\
\text { subsurface }\end{array}$} & \multirow{2}{*}{138,755} \\
\hline & no crack & $291 \mu m$ & & \\
\hline
\end{tabular}

Table 2 contains the surface measurement of the failure crack as tracked on the acetate replicas. Due to the relatively rapid propagation of these cracks and the generally long incubation period, the cracks were hard to track and, at best, two replicas captured the growth of the cracks. The initiation depth is the approximate depth to the center of the grain (facet) that lead to failure. The smallest crack that was captured on a replica was 78 $\mu \mathrm{m}$ in surface length and required an additional 29,404 cycles to 
grow to failure - the longest "propagation" life of those measured. The other samples generally indicated a growth life of 12 to $20 \mathrm{~K}$ cycles from "no crack" to failure. This could be misleading due to the slight subsurface location of the crack initiation. Specimen 06024 indicated only 2,658 cycles from "no crack" to failure. The fracture surface of this specimen indicated that a crack bifurcated which might have hid the actual initiation site.

\section{Crack Growth Results}

The typical results for the crack growth tests are shown in figure 4 along with the Paris Law fits through the upper, linear portion of the curves. There is a small difference in crack growth resistance for the two variants of Waspaloy but the trends were similar for the repeated tests. It is apparent that the material follows the intuitive grain size dependence in that the coarser material has a slightly greater resistance to crack propagation. The Paris law coefficients for the two microstructural variant are shown in Table 3 indicating that the differences are indeed small.

Table 3, Paris Law coefficients for the two microstructural variants of Waspaloy

\begin{tabular}{|l|c|c|}
\hline Microstructure & Paris Coefficient & Paris Exponent \\
\hline Conventional & $6.1147 \times 10^{-12}(\mathrm{~m} /$ cyc $)$ & 2.990 \\
\hline Fine + ALA & $8.1145 \times 10^{-12}(\mathrm{~m} / \mathrm{cyc})$ & 2.959 \\
\hline
\end{tabular}

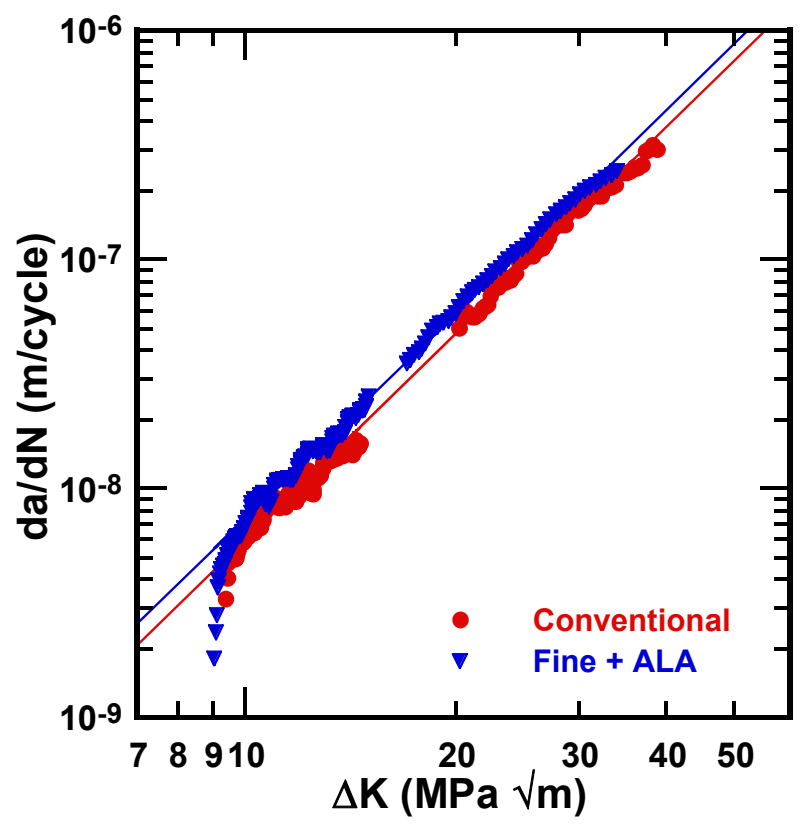

Figure 4, Crack growth rates and Paris Law fits for the two variants of Waspaloy; $538^{\circ} \mathrm{C}, \mathrm{R}=0.05, \sigma_{\max }=955 \mathrm{MPa}, 1 \mathrm{~Hz}$.

\section{Fracture Mechanics Approach to Minimum Fatigue Life}

Earlier studies $[5,6]$ indicated that the shortest fatigue life can be predicted using fracture mechanics and the size of the crack initiation features in the material. Fractography of the specimens indicated that there was a clear link between the size of the surface connected (or near surface) facet and the overall fatigue life. Figure 5 shows the initiation site for the shortest life specimen for the fine + ALA (A), and conventional (B) microstructures. The initiation site for specimens having a long life that failed from a surface or near surface grain is shown in figure 6 for the fine + ALA (A), and conventional (B) microstructures. A comparison of the initiation sites for the fine + ALA microstructure, Figures 5 (A) and 6(A) shows the clear size difference in the initiation facet that is assumed to be the initiation controlling feature. Figures 5 (B) and 6 (B) showing short and long life initiation sites for the conventional microstructure are not as convincing. In Figure 5(B) it appears that several grains may have contributed to the crack initiation while a single facet is clear in Figure 6 (B). The mechanism of crack initiation in Waspaloy is clearly not controlled by defects. In all cases the initiation site is due to the single large grain or cluster of closely aligned grains that are oriented preferentially for crack initiation. Generally it appeared that a single grain initiated the cracks that grew to failure. The analysis of the fracture surfaces indicated that the initiation plane is inclined to the loading axis by an angle around $45^{\circ}$ but is highly variable. It is possible that a cluster of closely aligned grains acted as a single grain to initiate a crack, but that was not apparent from an examination of the facets on the fracture surface (If they are closely aligned, they would appear as a single grain.). Nonetheless, the size of this grain (or cluster of aligned grains) is then the main material parameter that can be controlled by the processing of the material to the final form. Hence, any crack growth integration should use the distribution of grain sizes as the initial crack sizes.

The influence of crack growth on the total fatigue life of Waspaloy can be roughly assessed by integrating the crack growth rate, $\mathrm{da} / \mathrm{dN}$, from an initial crack size to a final size when the specimen breaks. In practice, though, the life is not very sensitive to the final crack size since the crack growth rate is very fast at the end of life. For the specimens in this study, the K (stress intensity factor) solutions were chosen from Foreman and Shivakumar [8]. Here $\mathrm{K}$ is calculated as,

$$
\mathrm{K}=\sigma_{o} F_{o}(\lambda) \sqrt{\pi a}
$$

where,

$$
\begin{aligned}
& F_{o}=g(\lambda)\left[0.752+2.02 \lambda+0.37(1-\sin \pi \lambda / 2)^{3}\right\rfloor \\
& g(\lambda)=0.92(2 / \pi)[(\tan \pi \lambda / 2) /(\pi \lambda / 2)]^{1 / 2} \cos \pi \lambda / 2
\end{aligned}
$$

and,

$$
\lambda=a / D
$$

with a being the crack depth and $\mathbf{D}$ being the diameter of the test bar. Using this solution the crack is assumed to propagate as a circular arc into the test bar. This appeared generally correct as the final crack size was quite small and not well defined in this material. 

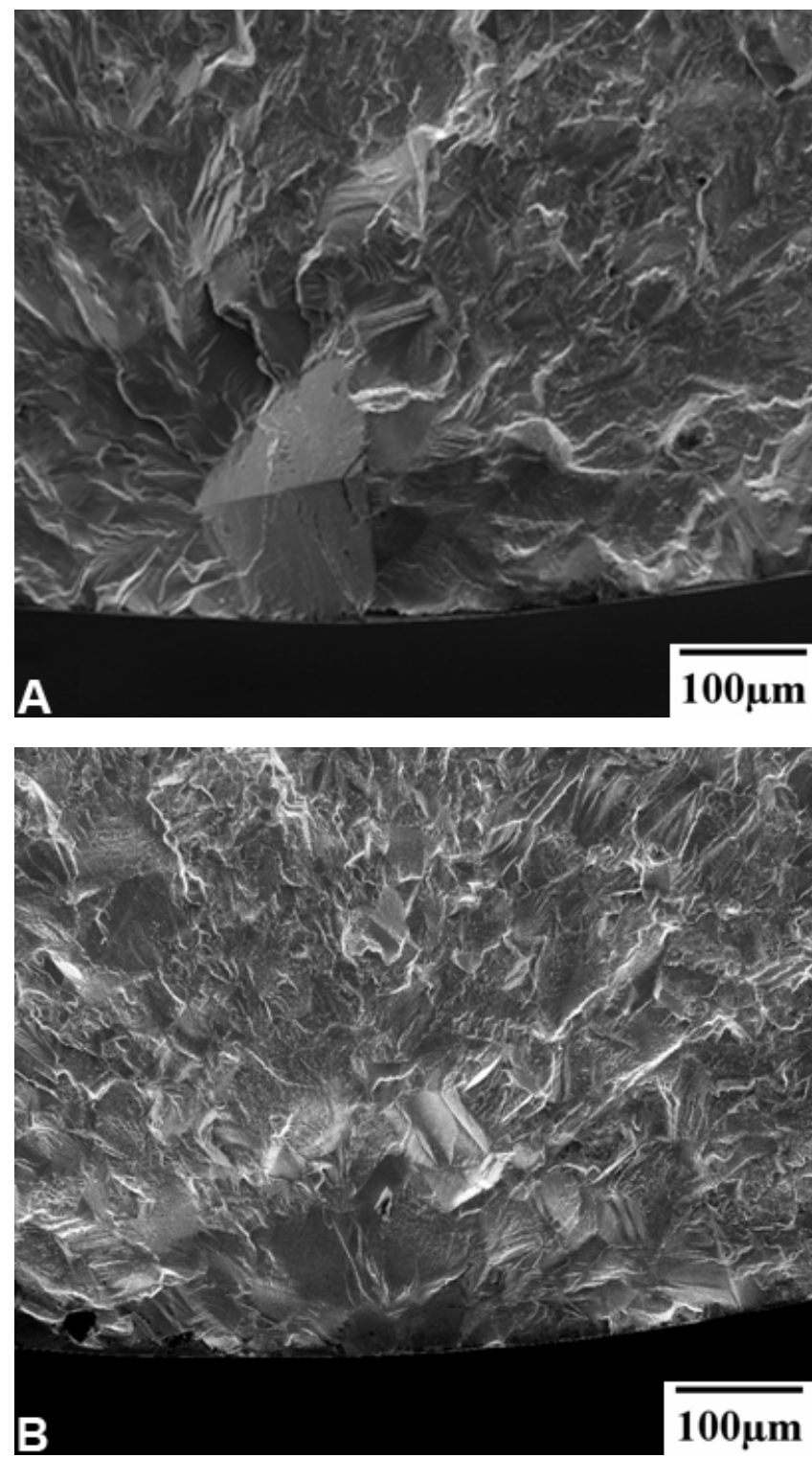

Figure 5, Crack initiation sites in the shortest life specimens for each microstructure; A) Fine +ALA, Nf $=27,570$ cycles, B) Conventional, $\mathrm{Nf}=24,852$ cycles

The total crack growth life is calculated by integrating (1) from an initial crack size to a final crack size. A simple Paris Law was used for the crack growth law with no threshold. The constants are in Table 3. In this study, a range of initial crack depths was chosen based on the grain size distribution shown in Figure 2. That is, initial crack sizes were chosen as the largest grain in the distribution and the average grain in the distribution. In all cases the final crack depth was $1.5 \mathrm{~mm}$. As stated previously, the doubling the final crack sizes increases the total life by less than $2 \%$ in all cases.

The life integration results are shown numerically in Table 4 and graphically in Figure 7 . The minimum fatigue lives in Figure 7 fall remarkably close to the shortest propagation lives predicted by the integration of the crack growth rate. Using the largest grain size as the initial crack depth may be conservative, but typically having a large grain that is just below the surface of the specimen can result in a very short crack growth life - so this might be a truly worst case fatigue life.
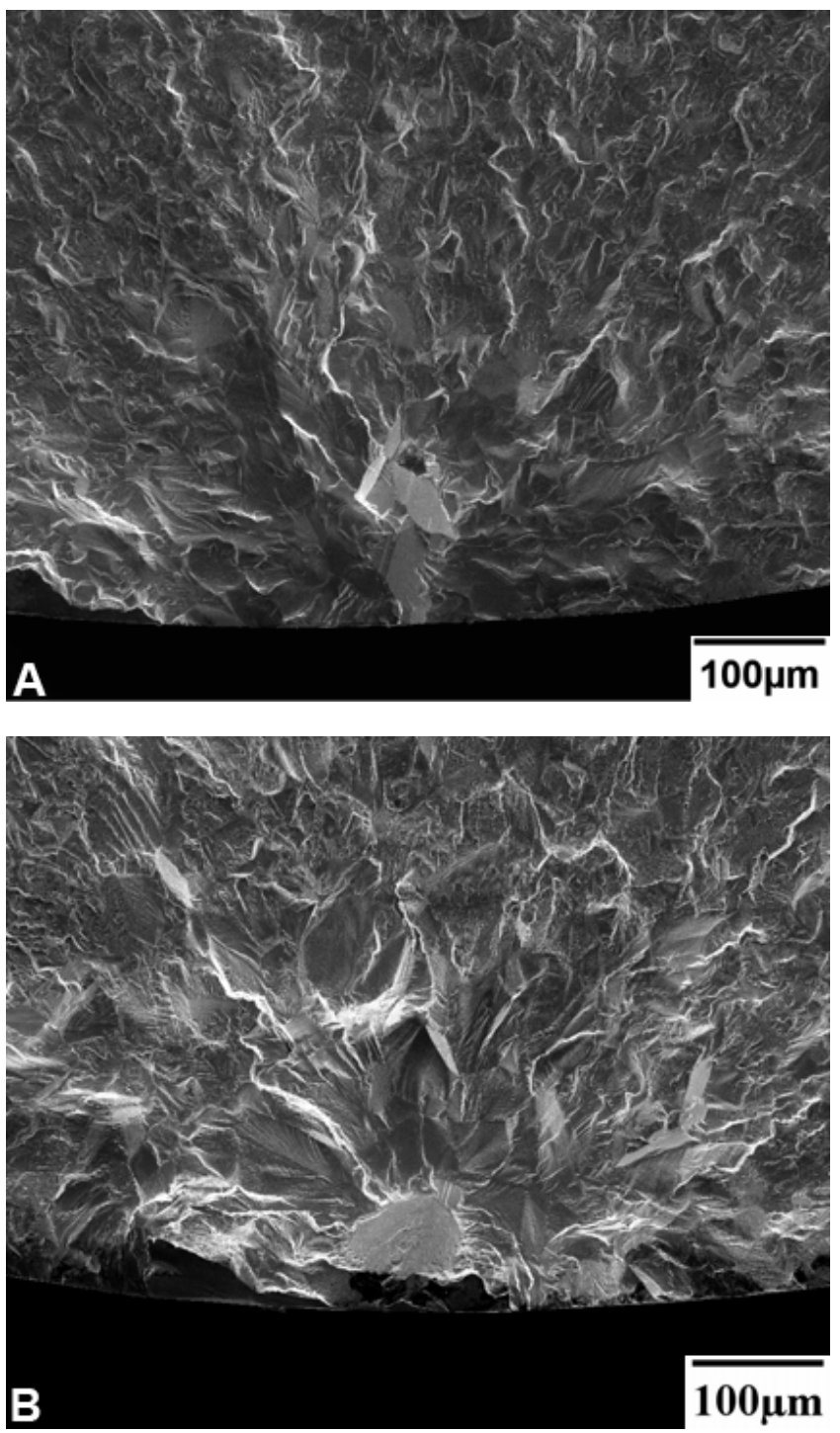

Figure 6, Surface crack initiation sites for long life specimens; A) Fine + ALA, Nf $=437,451$ cycles, B) Conventional, $\mathrm{Nf}=133,870$ cycles.

Table 4, Initial crack sizes and computed crack propagation life for a final crack depth of $1.5 \mathrm{~mm}$

\begin{tabular}{|c|c|c|}
\hline Microstructure & $\begin{array}{c}\text { Initial Crack } \\
\text { Depth }(\boldsymbol{\mu m})\end{array}$ & $\begin{array}{c}\text { Propagation } \\
\text { Life (cycles) }\end{array}$ \\
\hline \multirow{2}{*}{ Conventional } & 80 & 21,530 \\
\cline { 2 - 3 } & 17.8 & 56,667 \\
\hline \multirow{2}{*}{ Fine + ALA } & 100 & 15,018 \\
\cline { 2 - 3 } & 10.6 & 61,155 \\
\hline
\end{tabular}




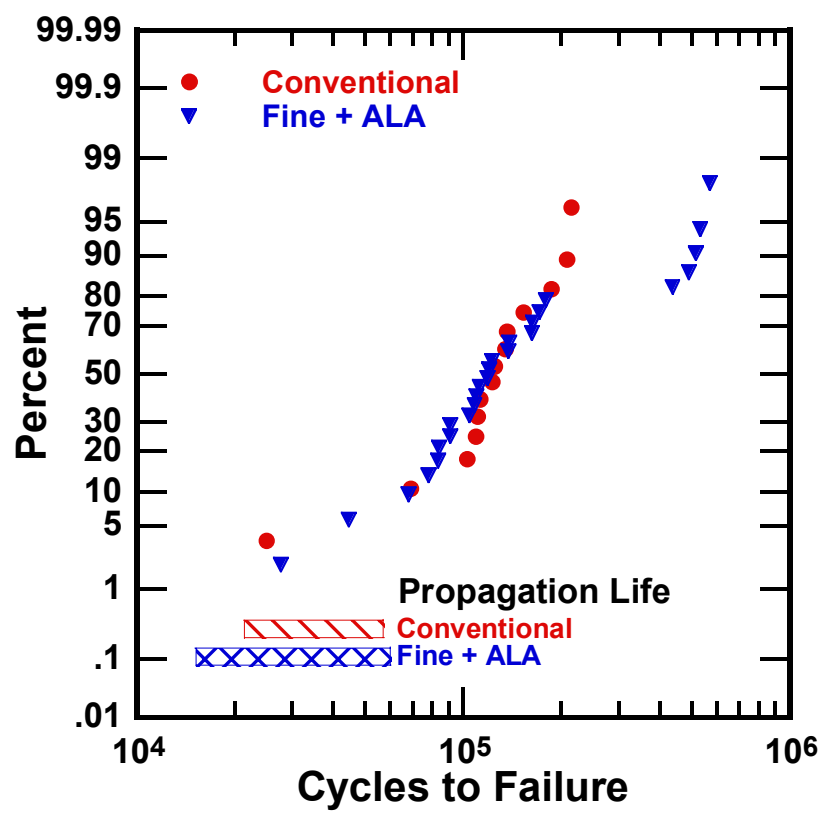

Figure 7, Range of crack propagation life for two variants of Waslapoy with initial crack sizes equal to the largest measured grain and the average grain size; $538^{\circ} \mathrm{C}, \mathrm{R}=0.05, \sigma_{\max }=955 \mathrm{MPa}$, $1 \mathrm{~Hz}$.

Earlier work by Jha, et al, [6] did demonstrate the importance of including small crack growth results in the accuracy of predicting the worst case fatigue performance of a material. In their study, the materials were an $\alpha+\beta$ titanium alloy and a powder metallurgy disk alloy, both having a fine grain size. The Waspaloy in this study had a considerably coarser microstructure than those materials and the initial crack size likely was large enough to minimize the influence of small cracks.

The short life fatigue distribution is predicted by a fracture mechanics approach, but the majority of the data falls to the right of the life predicted by the average grain size. This indicates that, generally, there is a significant contribution from crack initiation to the total fatigue life for the majority of the samples tested in this study. Since the five long life bars for the fine + ALA material fall in a different distribution, it is probable that they represent a group of test bars that did not contain ALA grains. Therefore there may be material process options that could improve the fatigue performance beyond the current understanding of microstructure control. However, there is still a possibility that a cluster of fine grains having similar orientations could act as a single large grain. Such an examination was beyond the scope of the current program.

Finally, in predicting the useful life of fracture critical rotating structures, the lower fatigue life appears to be intrinsically linked to the current USAF damage tolerance requirement. However, understanding the aspects of fatigue crack initiation is also critical to get the most use out of these structures.

\section{Conclusions}

This study examined the fatigue difference of two microstructural variants of Waspaloy, fine + ALA having an average grain size of ASTM 8.5, ALA 2, and conventional having an average grain size of 7. It appears that the larger tail of the grain size distribution in
Waspaloy controls the lower bound fatigue capability. It is clear that it is not sufficient to describe Waspaloy by an average grain size as it is the large size of the distribution of grains present in the material control the fatigue response. Acetate replication demonstrated that the left tail of the fatigue life distribution could largely be due to crack propagation and the fracture mechanics calculations further support this claim. Hence, the role of microstructure control should be to minimize the locations for crack initiation to strongly affect the overall fatigue life for this material. Additional studies should be conducted in a similar matter to assess the probability that a number of closely aligned grains could act as a single large grain - thereby negating any benefit of grain size control.

\section{Acknowledgement}

Support for this work by MLB under the contract FA-8650-04-C5200 is gratefully acknowledged.

\section{References}

1. R.E. Bailey, "Some effects of Hot Working Practice on Waspaloy's Structure and Tensile Properties," Superalloys 1972, (Warendale, PA: TMS, 1972), pp. J1-J21.

2. Engine Structural Integrity Program, (Report MIL-HDBK1783, ASC/EN, Wright-Patterson AFB, OH 2004).

3. S.K. Jha and K.S. Ravi Chandran, "An unusual fatigue phenomenon: duality of the $\mathrm{S}-\mathrm{N}$ fatigue curve in the $\beta$ titanium alloy Ti-10V-2Fe-3Al,"Scripta Materialia, 48(8), (2003), 1207-1212.

4. K. A. Schwendiman, "Critical Life Prediction Research on Botron-Enhanced Ti-6Al-4V," (MS thesis, Air Force Institute of Technology, Wright-Patterson AFB, OH, 2007).

5. M.J. Caton, et al, "Divergence of Mechanisms and the Effect on the Fatigue Life Variability or Rene' 88DT," Superalloys 2004, K.A. Green, et al., eds, (Warendale, PA: TMS, 2004), 305-312.

6. S.K. Jha, M.J. Caton, J.M. Larsen, "A new paradigm of fatigue variability behavior and implications for life prediction," Material Science \& Engineering, A468-470 (2007), 23-32.

7. M.L. Brogdon, "The effect of as-large-as grains on the hightemperature fatigue life of Waspaloy," (MS thesis, University of Dayton, Dayton, OH, 2006).

8. R.G. Forman, and V. Shivakumar, "Growth Behavior of Surface Cracks in Circumferential Plane of Solids and Hollow Cylinders," Fracture Mechanics: $17^{\text {th }}$ Volume, ASTM STP 905, J.H. Underwood, et al., Eds., (Philadelphia, PA: ASTM, 1986), 59-74. 